\title{
Serviços de Saúde Materna como estratégia biopolítica de disciplinamento dos corpos em Cuba
}

\author{
Maternal health services in Cuba - a biopolitical strategy for disciplining \\ pregnant women' bodies (abstract: p. 14)
}

\section{Servicios de Salud Maternal como estrategia biopolítica de disciplinamiento de los cuerpos en Cuba (resumen: p. 14)}

\section{Rosane Machado Rollo(a)}

$<$ rollo@portoweb.com.br>

Adriana Roese Ramos ${ }^{(\mathbf{b})}$

Cristianne Maria Famer Rocha(c)

$<$ cristianne.rocha@ufrgs.br> iD (a) Bacharel em Saúde Coletiva. Rua Itapuí, 392, Sarandi. Porto Alegre, RS, Brasil. 91130-420.

(b) Departamento de Assistência e Orientação Profissional, Escola de Enfermagem (EE), Universidade Federal do Rio Grande do Sul (UFRGS). Porto Alegre, RS, Brasil.

(c) Departamento de Saúde Coletiva, EE, UFRGS. Porto Alegre, RS, Brasil.

A saúde materno-infantil se apresenta como uma das áreas prioritárias na atenção à saúde em Cuba. 0 presente artigo tem como objetivo analisar os serviços de saúde materna (chamados em Cuba de Hogares Maternos) - onde as mulheres são internadas para receberem cuidados médicos pelo tempo necessário nas situações de risco ou complicações na gestação - enquanto uma estratégia biopolítica. Nesse sentido, buscamos problematizar a utilização dessa estratégia de docilização e disciplinamento das gestantes, ao mesmo tempo em que reconhecemos ser esta uma potente estratégia de governo para preservação da vida em Cuba.

Palavras-chave: Cuba. Saúde materno-infantil. Centros de saúde materno-infantil. Gravidez de alto risco. Serviços de saúde materna. 


\section{Breve panorama do Sistema Nacional de Saúde cubano}

No campo da saúde, Cuba atravessa uma transição demográfica avançada, caracterizada por uma conjunta baixa fertilidade e baixa mortalidade, o que acarreta aumento da esperança de vida ao nascer (oitenta anos em 2017). Esses fenômenos levaram a um declínio na taxa de crescimento populacional e ao envelhecimento da população.

Em relação à saúde materno-infantil, em específico, Cuba se destaca por estar entre os países da América Latina com melhores indicadores. Entre os resultados mais relevantes até 2017, estão a redução da mortalidade infantil e mortalidade em menores de cinco anos para 4,0 e 5,5 mortes por mil nascidos vivos, respectivamente. A taxa de mortalidade materna para 2017 é de 38,3 mortes por cem mil nascidos vivos, $8,6 \%$ menor que em 2016. Outro aspecto a ser ressaltado é a porcentagem de partos atendidos em instituições de saúde, que tem permanecido constante (99,9\%) nos últimos anos ${ }^{1-3}$.

Tal realidade, fruto das transformaçóes ocorridas após a Revolução, de acordo com Osa ${ }^{4}$, está profundamente marcada pelas conquistas obtidas na transição socialista, que ocorreram na ilha a partir de 1960 e que operaram mudanças importantes com a criação do Sistema Nacional de Saúde (SNS).

O SNS cubano é o primeiro sistema único, gratuito e integral nas Américas, com cobertura universal e direção central do Ministério Nacional de Saúde Pública (MINSAP). Regulado, financiado e com a prestação de serviços exclusiva do Estado, é um sistema que preconiza a saúde como direito social inalienável.

A atenção à saúde estrutura-se em quatro níveis: primário, secundário, terciário e quaternário. A prioridade se destina aos cuidados de saúde do nível primário, com ampla cobertura e baixa densidade tecnológica, tendo como proposta ordenadora $\mathrm{o}$ Programa Médico e Enfermeira de Família (PMEF). Instituído em 1984, o PMEF foi uma das estratégias que possibilitou que Cuba se tornasse uma potência mundial na área da saúde, bem como uma referência para a organização dos sistemas de saúde de diversos países. O nível secundário, responsável pela resolubilidade de 15\% dos casos de saúde, envolve menor cobertura e maior densidade tecnológica e é composto por hospitais regionais e municipais. Os níveis terciário e quaternário são de cobertura mínima e densidade tecnológica máxima e utilizados quando há necessidade de internaçốes, por meio de serviços como hospitais e institutos especializados 5 .

Dentre os programas prioritários, em Cuba, destaca-se o Programa de Atenção Materno-Infantil (Pami), em que ocorre grande investimento para a implementação e consolidação de açóes no cuidado da mãe e da criança. É prova disso o fato de que a taxa de mortalidade infantil está, há dez anos consecutivos, abaixo de cinco por mil nascidos vivos (tendo diminuído de cerca de sessenta por mil nascidos vivos nos anos 1950 para quatro no fim 2017, a mais baixa da história cubana). Outro indicador - que também aponta para o fortalecimento desse programa e que se encontra em franca queda - é o do baixo peso ao nascer, que teve uma redução de 11,7\% em 1975 para 5,1 em 2017. Tais indicadores colocam Cuba em destaque internacional em relação à mortalidade infantil ${ }^{1,6}$.

Dentro do Pami, um dos principais serviços oferecidos é o Hogar Materno ou Palácio da Maternidade (como também são conhecidos em Cuba). É um equipamento vinculado à Atenção Primária em Saúde (APS), que garante a prestação de cuidados 
de saúde a todas as gestantes ${ }^{7}$. Seu principal objetivo é o de minimizar e/ou prevenir as complicações decorrentes de uma gestação com evidentes e potenciais fatores de risco, evitando a morbidade e/ou mortalidade materno-infantil ${ }^{8}$.

Neste sentido, o Hogar Materno, certamente, é um dos principais pilares para a manutenção dos bons indicadores da saúde materno-infantil cubana. Por outro lado, esse dispositivo de saúde instiga reflexões sobre a forma como são conduzidas certas estratégias biopolíticas para o controle e a manutenção dos índices alcançados.

A partir dessas constatações, nossa intenção é analisar os Hogares Maternos enquanto uma estratégia biopolítica (para a população) e disciplinamento dos corpos das mulheres grávidas.

\section{Hogar Materno embalando a vida: o lado oficial da história}

O Hogar Materno tem sua origem em Cuba no século XVIII, mais precisamente, em 1711, com a inauguração da Casa de Niños Expósitos, também conhecida como Casa Cuna. Em 1852, essa instituição foi fundida com a Real Casa de Maternidade e Beneficiencia (que havia sido criada em 1792) e, a partir daí, passou a se chamar Real Casa de Maternidad y Beneficencia de La Habana'. Só muito tempo depois, no fim da década de 1940, criou-se uma sala com quatro camas no Hospital Maternidade Municipal América Arias, em Havana, com o nome de Hogar Materno ${ }^{10-12}$.

Alguns países da América Latina também possuem equipamentos concebidos como instituição não hospitalar para dar proteção à gestante próxima ao parto, como Colômbia, Nicarágua, Hondura, Chile e Brasil ${ }^{11}$. Entretanto, apesar de similares na concepção do cuidado às gestantes, os nomes podem se apresentar de forma diversa. Por exemplo, na Colômbia, o equipamento também é chamado pelo nome de Hogar Materno, já no Brasil, de Casa de Gestante, Bebê e Puérpera.

De acordo com García', o desenvolvimento histórico desse equipamento de saúde, em Cuba, após a Revolução, constituiu-se em três etapas. Na primeira (1962-1969), o objetivo fundamental da criação dos Hogares Maternos foi o de incrementar o indicador do parto institucional nos municípios onde as condições geográficas eram desfavoráveis, mediante o alojamento de gestantes que se encontravam nas últimas semanas de sua gestação ${ }^{10}$. No fim dessa etapa, havia 15 equipamentos?.

A segunda etapa (1979-1989) foi caracterizada pelo desenvolvimento numérico e de extensão territorial. Em 1975, os Hogares já somavam 56 e, em 1988, chegaram a um número de 142, estendendo-se não só às zonas rurais, mas também às áreas urbanas, em diferentes cidades?.

A terceira fase começou juntamente com a crise econômica que assolou o país em 1990. Em face disso, o crescimento numérico de instituçôes e camas foi muito discreto, mantendo-se apenas as atividades assistenciais, de promoção e de educação em saúde, que buscavam garantir, ao menos, a alimentação adequada das gestantes ${ }^{12}$.

Desde sua criação, os Hogares Maternos continuam com a responsabilidade de hospedar e fornecer cuidados para mulheres que apresentam algum risco durante a gravidez, especialmente aquelas que vivem em áreas de difícil acesso ou que têm problemas nutricionais ou sociais em sua própria casa. Entretanto, a partir dos anos 1990, novos centros obstétricos foram criados e ocorreram importantes transformações 
nas condições de comunicação e de acesso às áreas mais remotas do país, fatores que produziram mudanças significativas na saúde materno-infantil ${ }^{9}$.

Mais recentemente, transformaçóes sociossanitárias deram origem a uma quarta etapa, na qual o número de Hogares diminuiu em mais de 50\% - passando de 336 para 143 - entre 2010 e 2011. Todavia, apesar da diminuição drástica de equipamentos, os ingressos não caíram na mesma proporção - houve um decréscimo em torno de apenas $15 \%$ - em virtude da otimização de processos, como o índice ocupacional, rotação de camas e integração com as redes vinculadas ao trabalho da instituição ${ }^{13}$. Depois dessa variação, o número de Hogares permanece praticamente estável nos anos que se sucedem, chegando a 131 nos dias de hoje ${ }^{3}$.

Atualmente, os Hogares Maternos recebem gestantes que passaram por avaliação da equipe de profissionais de saúde e tiveram constatada a existência de algum fator de risco gestacional, tanto biológico quanto social ${ }^{8,14}$. A avaliação dos fatores de risco orienta a organização do trabalho e a permanência (ou não) da gestante na instituição e, se esses fatores forem mais graves, a estadia da gestante é prolongada até o momento do parto $^{10}$.

Contudo, de acordo com García', existe uma tendência para que a gestante permaneça na instituição apenas durante o dia, indo para casa no fim desse período (regime de semi-internato). A estratégia gestante/dia que, em 1990, pelo contexto da crise, foi incluída como alternativa pontual (a fim de manter o atendimento), atualmente, é considerada como uma possível medida clínica, a fim de amenizar fatores de riscos sociais (como estresse, falta de repouso, etc). Essa modalidade é utilizada quando a gestante está exposta, em sua residência e/ou trabalho, a algumas situaçóes de risco que possam comprometer a evolução normal da gravidez.

Para os casos em que não é possível o cuidado domiciliar ou acompanhamento/ dia, a gestante permanece 24 horas na instituição ${ }^{14} \mathrm{e}$, para minimizar a mudança de habitação e evitar desequilíbrios emocionais, podem receber a visita da família. No Hogar Materno, o cuidado às gestantes acontece cotidianamente, por meio de algumas açôes educativas, preventivas e assistenciais.

Cada Hogar Materno é coordenado por um diretor (sempre um profissional médico), responsável por garantir o cumprimento das açôes previstas. Outros profissionais compóem a equipe, dependendo das atividades e dos convênios estabelecidos com outras instituiçóes (em nível local). Já as enfermeiras atuam em tempo integral ${ }^{13,14}$.

Os Hogares Maternos devem estar localizados perto de algum hospital que tenha atendimento ginecológico e obstétrico, a fim de possibilitar um rápido translado da gestante, em caso de urgência. Esse hospital se responsabilizará por parte de seu funcionamento e supervisão.

Por fim, os Hogares são considerados instituições de baixa densidade tecnológica que têm em média de 25 a trinta camas e que devem ser de baixo custo operacional e de manutenção. Entretanto, mesmo estando classificados como de baixa densidade tecnológica, o Hogar tem se constituído como um importante equipamento no que tange à saúde materno-infantil. 


\section{Ferramentas teórico-metodológicas}

Este artigo é o recorte de uma investigação que originou a dissertação de mestrado da autora principal com orientação da segunda autora e seu objetivo principal foi analisar os serviços, estratégias e políticas do Sistema Nacional de Saúde cubano a partir das experiências das autoras, vivenciadas durante a realização do Curso de Atenção Primária em Saúde e Medicina Familiar, em La Habana, Cuba, em janeiro 2015, organizado e oferecido pela Escola Nacional de Saúde Pública (Ensap), do Ministério de Saúde de Cuba.

O curso contou com atividades teórico-práticas: aulas ministradas por professores da Ensap e visitas a serviços de saúde para melhor conhecer o Sistema Nacional de Saúde cubano. Durante a visita ao Hogar - previamente escolhido pela coordenação do curso -, tivemos a oportunidade de conhecer e conversar com os profissionais/ trabalhadores, as gestantes e o gestor do local.

Para analisar os Hogares Maternos enquanto estratégia biopolítica, utilizamos algumas ferramentas foucaultianas. Entretanto, é importante antecipar que não pretendemos avaliar, muito menos apresentar verdades a respeito dos Hogares ou da saúde materno-infantil cubana. Também não se trata aqui de examinar se os mecanismos utilizados são efetivos, tampouco questionar as intervençôes realizadas sobre a vida dos sujeitos (no caso, as gestantes). Nossa intenção, bem mais modesta, é tão somente visibilizar e problematizar algumas dessas estratégias utilizadas para a manutenção da vida e o alcance de certos indicadores.

Assim, em que pese a utilização de outros conceitos foucaultianos ao longo deste texto, cremos ser importante referir como Foucault compreendia a biopolítica:

[...] a maneira pela qual, a partir do século XVIII, se buscou racionalizar os problemas colocados para a prática governamental pelos fenômenos próprios de um conjunto de viventes enquanto população: saúde, higiene, natalidade, longevidade, raça. [...]. Essa nova forma de poder se ocupará, então: 1) Da proporção de nascimentos, de óbitos, das taxas de reprodução, da fecundidade da população. Em uma palavra, da demografia. 2) Das enfermidades endêmicas: da natureza, da extensão, da duração, da intensidade das enfermidades reinantes na população; da higiene pública. 3) Da velhice, das enfermidades que deixam o indivíduo fora do mercado de trabalho. Também, então, dos seguros individuais e coletivos, da aposentadoria. 4) Das relaçóes com o meio geográfico, com o clima. O urbanismo e ecologia. ${ }^{15}$ (p. 59-60)

Segundo Gallo e Veiga-Neto ${ }^{16}$, Foucault, analisando a conformação histórica dos poderes, mostrou que vivemos - naquilo que se convencionou chamar de modernidade - três modelos de exercício de poder: o de soberania, o disciplinar e o biopoder, que não se excluem, mas se complementam. Para Foucault ${ }^{17}$ (p. 128), a partir da época clássica, ocorreu uma profunda mudança nas formas/relaçóes de poder. Antes, no poder soberano, os bens e as vidas dos súditos podiam ser tomados pelo governante, já que era seu o "direito de causar a morte ou deixar viver". Com o surgimento do capitalismo industrial, ocorreu um deslocamento do exercício e das relações de poder, de uma dimensão jurídica para uma dimensão biológica. Então, diferentemente do poder soberano - que fazia morrer ou deixava viver -, na sociedade 
disciplinar, algumas dinâmicas foram transformadas em função de “[...] o poder disciplinar ser por efeito um poder que, em vez de se apropriar e retirar, tem como função maior adestrar; ou sem dúvida adestrar para retirar e se apropriar ainda mais e melhor"18 (p. 149). Assim, segundo Souza ${ }^{19}$, o poder disciplinar se dirigia - e ainda se dirige na contemporaneidade - aos indivíduos (em nosso caso, às gestantes) e, mais precisamente, aos seus corpos, tendo como objetivo o seu adestramento e sua normalização.

Todavia, as estratégias de poder não se encerram nas ferramentas disciplinares. Para Foucault ${ }^{17}$, em consonância com as técnicas de controle focadas na disciplina, na vigilância e na normatização, outras técnicas - que ampliam a força da disciplina para além do corpo do indivíduo (corpo-máquina) - são ativadas com a criação dos Estados nacionais para atuarem sobre o corpo coletivo (dos múltiplos indivíduos), ou seja, sobre a população (corpo-espécie). Tais processos e técnicas permitiram, por exemplo, a quantificação dos sujeitos e os cálculos de algumas regularidades dos processos vitais coletivos. A essa técnica/estratégia de poder disciplinar coletiva, Foucault deu o nome de biopoder ${ }^{20}$. Conforme Souza ${ }^{19}$, para Foucault, o biopoder é exercido de forma positiva sobre a vida, de modo a orientar a sua gestão no nível individual e populacional. Nesse sentido, são considerados os traços biológicos comuns que envolvem a espécie humana, por meio das biopolíticas, e os comportamentos individuais que podem ser disciplinados de modo a fazer com que os diferentes sujeitos se engajem no funcionamento das normas seguidas pelas populaçóes. Rocha ${ }^{21}$ explica como o poder disciplinar e o biopoder se utilizam das disciplinas como estratégia de poder:

O poder disciplinar e o biopoder se utilizam das disciplinas para organizarem os pensamentos (disciplina-saber) e as práticas (disciplina-corpo) que sancionam e prescrevem comportamentos através da repetição, do treinamento, do exercício e do exame no sujeito "livre", que possui direitos e deveres e que acredita em sua autonomia e responsabilidade na tomada de suas próprias decisões. ${ }^{21}$ (p. 48)

Assim, com a aproximação das instâncias biológicas e políticas, o viver e o morrer não estavam mais relacionados ao acaso, mas, em parte, ao campo do controle do saber e à intervenção do poder. Nessa direção, as biopolíticas designam a entrada da vida e seus mecanismos no domínio dos cálculos estatísticos. O foco das biopolíticas se encontra em gerir a vida das populaçóes e produzir conhecimentos a fim de melhor administrá-la, transformá-la e, sobretudo, aperfeiçoá-la ${ }^{19}$.

Nesse sentido, Foucault ${ }^{22}$ toma a medicina/saúde como uma estratégia biopolítica e a define como uma importante técnica de controle das sociedades capitalistas - que buscam o corpo com o viés da produção - sobre os indivíduos, que vai se efetuar no corpo e para o corpo. No entanto, se antes o enfoque se direcionava ao fazer/ produzir - com o intuito de obter resultados no aspecto econômico -, sob o efeito das biopolíticas, o objetivo se constrói na lógica de investimento em condições e regulações ligadas à vida dos indivíduos na direção de se extrair maiores níveis de produção em relação aos anteriores ${ }^{19}$. Agora, a partir de dados estatísticos relacionados a outros saberes técnicos e científicos, a saúde e o biológico são transformados em risco e naquilo que poderíamos ascender. Nessa perspectiva, segundo $\mathrm{Medeiros}^{23}$, ligar 
questôes como mães/filhos, controle de natalidade e mortalidade infantil faz com que a saúde funcione como estratégia biopolítica, a partir de determinados marcadores de risco e índices de desenvolvimento.

Portanto, uma estratégia biopolítica - como referimos ser o Hogar Materno cubano - trata a população (enquanto conjunto de seres vivos coexistentes) com técnicas e saberes específicos, capazes de diminuir as chances de morrer e aumentar as de $\operatorname{viver}^{24}$. Tal como indica a expressão, é uma política para (potencializar) a vida.

\section{(Des)acomodação: um olhar foucaultiano sobre o Hogar Materno}

A oportunidade de visitar e conhecer um Hogar Materno nos permitiu compreender melhor a sua dinâmica de funcionamento, para além das questóes técnico-científicas. Em cada detalhe, o (in)visível e o (in)dizível nos instigavam a problematizar o Hogar com o necessário deslocamento do foco de análise da gestão do corpo biológico e do espaço institucional para os discursos que os reproduzem.

De imediato, nossas percepções fizeram conexão com os discursos dos modos de ser das mulheres/mães - especialmente de sua função reprodutiva - e como esses discursos poderiam ser pensados no contexto de uma modalidade de funcionamento das relações entre as ciências (saber) e as relaçóes de poder, a partir do conceito de biopolítica.

Nos Hogares Maternos, a saúde da gestante (e do feto) é vista/considerada como de risco, algo que deve ser previsível, disciplinável, tornando o futuro presente, de tal forma que a estratégia de cuidados intensos à gestante - fomentada pelo Estado cubano por meio desse equipamento - busca, intensa e incessantemente (de preferência, 24 horas por dia e, se necessário, muitos meses durante a gestação), aperfeiçoar os mecanismos de poder baseados em uma espécie de resguardo, que tem por objetivo - além de diminuir os riscos da morbidade e aumentar a natalidade manter a vida.

É o próprio Estado, equipado com estruturas oficiais de análises estatísticas acopladas às estruturas decisórias de poder - como a vigilância epidemiológica -, que cria um discurso capaz de validar a intervenção política por meio de limites aceitáveis, ou seja, ditos "normais"22. No Hogar Materno, o Estado cubano, ao identificar as gestantes de risco, indica também quais modos são saudáveis, adequados ou arriscados de se viver a gravidez. Segundo Foucault ${ }^{22}$, essa pedagogia de condutas, por meio do agrupamento e classificação dos corpos, é fundamental em uma economia biopolítica de disciplinamento dos corpos individuais e da administração da população.

Um dos aspectos que nos chamou a atenção foi a disposição arquitetônica do espaço físico. Apesar de sua aparente simplicidade, os Hogares ambicionam acolher as gestantes em um espaço que deve ser aconchegante e o mais próximo possível de sua casa (ou hogar, em espanhol). Assim, dispor os espaços e organizá-los de acordo com a lógica de uma casa permite, "sem (aparentes) intencionalidades”, organizar disciplinadamente as pessoas, de modo a forjar a educação das condutas e dos corpos daquelas gestantes.

Essa técnica de dominação, por meio da delimitação de espaços e da disciplina corporal, de acordo com Gallo ${ }^{25}$, constitui-se em uma verdadeira anatomia política, que individualiza a relação de poder. Para o autor, as sociedades disciplinares foram (e são) responsáveis pela individualização do poder, pelo processo de subjetivação e pelas novas 
formas de convívio social e de relações de poder, em que a dominação é introjetada, criando uma ilusão de liberdade e autonomia, em que cada um de nós é, supostamente, responsável por suas escolhas. Entendemos que nossa sensação de desacomodação naquele Hogar também foi consequência dessa "ilusão" de autonomia, verbalizada nos discursos feitos pelos sujeitos (médico, trabalhadoras, usuárias) que utilizam a casa. Afinal, com tantos avanços alcançados, ninguém ousa questionar a eficiência (ou a necessidade) de tal estratégia.

Não obstante as características físicas, organizativas e estruturais do Hogar não se apresentarem como as de um hospital e estarem contempladas como um equipamento da atenção primária, percebemos que, ainda assim, as gestantes são interpeladas pelo discurso biomédico, não apenas pela necessidade de serem saudáveis, mas, sobretudo, por se constituírem como guardiâs de uma nova vida. Então, para controlar esses corpos grávidos, a disciplina ali vigente se utilizava de alguns instrumentos, tais como: a vigilância hierárquica, a sanção normalizadora e o exame, descritas por Foucault ${ }^{18}$ como as técnicas que combinam a hierarquia que vigia e a sanção que normaliza.

Por meio da articulação de todas essas tecnologias, a instituição conduzia a gestão daquele Hogar e de suas gestantes. Assim, a definição da internação e do tempo de permanência na instituição é feita por determinação médica, ou seja, o saber médico - o que não poderia deixar de pautar a conduta em um sistema de saúde médicocentrado - é "soberano" (indiscutível e inquestionável). Por meio do exame - técnica tanto de poder quanto de saber -, o médico esquadrinha, disseca, cataloga e classifica o corpo da gestante de modo a enquadrá-la em uma escala de risco gestacional. $\mathrm{Na}$ lógica do "risco", é permitido formular e justificar formas de controle e regulação em uma inscrição e captura dos sujeitos (das gestantes) por meio de microtecnologias de constituição das subjetividades da mulher/mãe.

Entretanto, não podemos esquecer que, para Foucault ${ }^{17}$, o poder acontece em uma relação de forças que pressupóe liberdade, pois o poder só pode ser exercido sobre sujeitos livres, que tenham diante de si um campo de possibilidades no qual diversas condutas podem acontecer. Assim, os dispositivos de controle utilizados pela sociedade para o exercício de técnicas/estratégias de poder e domesticação dos corpos (corpo grávido) são inseridos de forma tão discreta que a existência desses dispositivos - pela sociedade, em geral; e pelas usuárias, em particular - não é vista só como necessária, mas como legítima. Assim, não se trata de negar as condutas, recomendações ou exames a serem indicados para as gestantes durante o período pré-natal e/ou de internação no Hogar, mas de refletir como o controle deixa de investir exclusivamente no corpo e passa a focalizar a vida naquilo que se objetiva como risco.

Conforme informação do gestor do Hogar Materno visitado - médico especialista em ginecologia e obstetrícia -, as mulheres podem decidir não ficar nesse serviço. Entretanto, a normatização do local impacta nessa decisão, uma vez que as gestantes são definidas pelos profissionais de saúde - a partir de evidências e pressupostos científicos constituídos em regimes de verdade - como pacientes em situação de risco. Segundo Souza ${ }^{19}$, para que a evidência seja considerada uma verdade, é necessário que estejamos inseridos em determinados regimes de verdade, pois são esses regimes que moldam aquilo que define o verdadeiro e sobre o qual se desenvolve a governamentalidade ${ }^{(\mathrm{d})}$. Para Foucault, os regimes de verdade posicionam e constrangem os indivíduos frente ao verdadeiro, ou seja, é aquilo que determina ações e consentimentos frente ao que se (d) Em relação à

governamentalidade, esse foi um neologismo utilizado por Foucault ${ }^{26}$ para designar um conjunto de estratégias, conhecimentos e procedimentos aplicados sobre indivíduos, sobre grupos ou sobre populações de modo a conduzi-los de acordo com os interesses de uma racionalidade e de um objetivo maior. 
acredita ser a verdade. Nesse sentido, cada pessoa aceita a verdade sem que seja preciso fazer uso de violências ou imposições, pois a própria verdade molda o indivíduo ${ }^{18}$. Todavia, cabe ressaltar que Foucault, ao mesmo tempo em que começou a desenvolver o conceito de governamentalidade, também se distanciou da visão de que o biopoder e a biopolítica sejam indubitavelmente prejudiciais. Como toda relação de poder, as estratégias que visam regular e proliferar a vida são extremamente produtivas e, por isso mesmo, desejáveis e praticadas sem necessidade de coerção ou violências impositivas ${ }^{20}$.

No Hogar, a governamentalidade acontece pela condução das gestantes e do seu corpo grávido, a partir de um minucioso controle e do exercício de uma "coerção" contínua, não violenta, baseada nos discursos e regimes de verdades vigentes. Depois do ingresso, a gestante é internada (ainda que não seja um serviço hospitalar, o Hogar funciona como se assim o fosse), confiante de que aquela situação é a melhor para ela e para o bebê, ainda que fique longe do seu espaço familiar, até que o fator de risco se dissipe, seguindo as regras estabelecidas.

Estrategicamente colocadas em murais e cartazes, nas paredes do Hogar, essas regras eram facilmente identificadas. Mas o que mais saltava aos olhos eram as normas da casa quanto aos horários e às atividades que permeavam a vida das gestantes ao longo do seu dia e por todos os dias em que ali permaneciam.

Às 7h: despertar. Das 7h às 7h30: banho. Das 7 h30 às 8h30: café da manhã. Das 9h30 às 10h: merenda. Das 11h30 às 12h30: almoço. Das 12h30 às 14h: descanso. Das 14h às 15h: atividades educativas. Das 15h às 15h30: merenda. Das $15 \mathrm{~h} 30$ às $18 \mathrm{~h}$ : recreação. Das $18 \mathrm{~h}$ às $19 \mathrm{~h}$ : janta. Das $19 \mathrm{~h}$ às 20h30: visitas. Das $20 \mathrm{~h} 30$ às $22 \mathrm{~h}$ : ver novelas brasileiras. Às $22 \mathrm{~h}$ : dormir.

A disciplina governa a vida das gestantes por meio do controle dos horários e da decomposição dos gestos e movimentos, ajustando o corpo a imperativos temporais, a fim de construir um tempo integralmente útil, para produzir o resultado desejado. Segundo Portocarrero ${ }^{27}$, gesto e corpo são postos em relação e a disciplina decompõe o ato em elementos, correlaciona o corpo com o gesto e articula o corpo com o objeto. Em nosso caso, são gestantes docemente disciplinadas aos horários previamente estabelecidos pelas normas do Hogar, a fim de eliminar o risco gestacional que as fez ingressar e permanecer no serviço.

À medida que íamos conhecendo o serviço (suas táticas e estratégias), outros estranhamentos surgiam. Contudo, também ficou visível que o gestor - ao descrever o serviço, o local e a forma de se relacionar com as gestantes - acreditava em seu trabalho e, principalmente, na maneira como os processos disciplinares-terapêuticos eram conduzidos.

Ouvimos (pelo gestor) que, antes da Revolução, eram as parteiras ou matronas as responsáveis por conduzir os partos, em casa ou fora dos hospitais. Porém, com o passar do tempo, essa atividade passou a ser realizada por enfermeiras obstétricas, e que, atualmente, os partos, quase todos hospitalares (99,9\%), são feitos quase que exclusivamente - salvo raríssimas exceçóes - por especialistas de ginecologia e obstetrícia (todos médicos).

Em Cuba, os profissionais entendem que, para o procedimento do parto ser seguro - para todos os casos -, são necessários o acompanhamento de um profissional médico 
e sua realização em um ambiente protegido e cercado por recursos capazes de reverter eventuais intercorrências. A defesa do parto hospitalar pelos profissionais de saúde está amparada não apenas no fato de que os partos ocorrem de forma absolutamente disciplinada, mas também no quanto esse processo de controle permite obter taxas e indicadores relacionados à temática materno-infantil considerados exitosos para um país da região das Américas e comparáveis a alguns países europeus.

Importante salientar que, para as gestantes com HIV/AIDS (o controle da doença é efetuado mensalmente $\left.{ }^{(e)}\right)$, todos os partos são feitos por cesariana. Além disso, as mulheres que vivem com HIV/AIDS vêm sendo interpeladas, de forma cada vez mais incisiva, a buscarem o desenvolvimento de crianças saudáveis e, portanto, sem HIV/ AIDS. Essa estratégia biopolítica resulta em uma série de recomendações e de ações, tais como: não amamentar, ingerir fortes medicações, realizar exames adicionais específicos, além daqueles aos quais todas as outras mães aderem (ou deveriam aderir) em um pré-natal ${ }^{28}$. Isso significa dizer que, para além de ampliar o sentido das aprendizagens necessárias ao exercício da gravidez e da maternidade, a condição de "soropositividade demanda, ao mesmo tempo, desaprendizagens complexas relativas ao que está estabelecido como 'dever ser' da maternidade"28 (p. 95).

Ao que parece, no contexto da maternagem soropositiva, paradoxalmente, o que se define como direito acaba sendo traduzido como dever, pois, por ser uma política de Estado, toda a gestante com HIV/AIDS é obrigada a fazer a cesárea para garantir que não haja o risco de transmissão do vírus da mãe para a criança. Assim, a fala de Pires sobre as mulheres grávidas no Rio Grande do Sul com HIV/AIDS também pode ser compreendida no contexto cubano: "quem e o que vai dizer o que significa fazer tudo direitinho para uma mulher grávida vivendo com HIV/AIDS será, em grande parte, o discurso biomédico"28 (p. 94).

Desse modo, caso a parturiente não concorde com a deliberação estatal da cesárea, ela passa a ser regulada por meio de determinadas classificações e sistemas de controle - alguns deles sustentados, justamente, pelo vocabulário do risco - que têm efeitos muito concretos na vida dessas gestantes. Pelo que pudemos apreender a partir dos discursos proferidos por diversos profissionais de saúde cubanos, caso a mãe não compreenda o "benefício da política" de que a obrigatoriedade do procedimento de intervenção da cesárea é para proteção dela e do bebê, o Estado evoca o direito de preservação da vida para garantir a saúde do bebê.

Todavia, esse discurso intervencionista não permeia apenas o sistema de saúde cubano e seus profissionais. Esse investimento em "fazer viver" as mulheres grávidas que vivem com HIV/AIDS, segundo Pires ${ }^{28}$, é enunciado explicitamente no Plano Global para Eliminar Novas Infecçóes por HIV/AIDS em Crianças até 2015 e Manter suas Mães Vivas ${ }^{29,30}$. Tais discursos têm por objetivo orientar as ações biopolíticas a serem executadas em nível global, regional e local e, em consequência disso, promover novos entendimentos sobre a segurança da vida, dentro e fora desses territórios ${ }^{18}$.

No Hogar, existiam casos em que o estado clínico, devidamente atestado pela conduta médica, necessitava de tratamento com internação. Contudo, para outras, internadas por estarem abaixo do peso, por exemplo, caberia questionar porque as mulheres, com questôes clínicas menos graves, são retiradas do seu convívio familiar, em um momento tão delicado, e aceitam tal situação tacitamente? Tem o Estado, ao evocar a vida como bem inalienável, o direito ou o dever de retirar estas mulheres de (e) Em 30 de junho de 2015, Cuba foi o primeiro país do mundo a ser reconhecido oficialmente pela Organização Mundial da Saúde (OMS) como nação que eliminou a transmissão materno-infantil de HIV e de sífilis ${ }^{28}$. 
dentro de suas casas, famílias e filhos? E esse suposto direito à vida do feto é um bem que tem supremacia ao direito a outros modos de vida daquelas mulheres, mesmo em se tratando de um país no qual o aborto é legalizado? Esses e outros questionamentos, necessários à reflexão aqui produzida, não buscam verdades ou certezas, tampouco apontar uma (in)adequação nas estratégias biopolíticas aqui analisadas. Na realidade, têm a intenção, bem mais modesta, de apenas ampliar a percepção de - e as possíveis análises sobre - algumas das tecnologias de poder utilizadas por alguns Estados nacionais, entre eles, Cuba.

Compreendemos que refletir sobre uma biopolítica - em que os regimes de verdade (apoiados em evidências) apontam para a aceitação de grande parte da população - pode causar estranhamento. Mas, nessa direção, cabe fazer uso das palavras de Foucault ${ }^{26}$ quando argumenta que os regimes de verdade são essenciais em nossas sociedades e, a partir desses regimes, grandes disputas são estabelecidas. Portanto, não se tratou, aqui, de questionar a forma de intervenção dessa biopolítica sobre a vida dos sujeitos, mas de torná-la visível/dizível e problematizá-la, a fim de mostrar as estratégias utilizadas para a manutenção e o alcance de certos indicadores.

\section{Para (in)concluir algumas ponderações}

O Hogar Materno é um equipamento que, do ponto de vista clínico e de manutenção de taxas e indicadores a patamares desejáveis, cumpre sua função, pois a gestante fica tutelada 24 horas ao dia e sua vida (assim como a do bebê) passa a ser governada pelo Estado, em sua dimensão sociobiológica, de maneira plena. Entretanto, esse equipamento provoca certos estranhamentos - certamente, muito mais nas autoras do que talvez em toda a sociedade cubana - na medida em que a política pública de saúde intervém no contexto e na produção de vida das pessoas, sem observar todos os aspectos nele inseridos. Em que pese termos sido informadas de que as gestantes tinham o "direito" de se afastar do tratamento, possivelmente as evidências e os saberes produzidos sobre elas não permitirão atitudes diferentes daquelas esperadas.

Assim, por que essas mulheres aceitam tal condução de suas vidas? Em nome de que/quem permitem - entre outras coisas - que alguém diga a elas o que e quando comer, o que e quando fazer, quem e quando podem visitá-las? Obviamente, não temos a pretensão de responder tais perguntas, tampouco tomar posicionamentos a favor ou contra a biopolítica utilizada tão estrategicamente pelos idealizadores e cuidadores dos Hogares Maternos. A intenção aqui foi apenas ensejar reflexões sobre os modos pelos quais as mulheres têm sido interpeladas pelos discursos sobre os riscos gestacionais e as práticas tidas como naturais sobre o corpo grávido da mulher/mãe, apesar dos movimentos de tensionamento dessas verdades. Trata-se tão somente de colocar em permanente movimento de estranhamento aquilo que é dito e, por isso, praticado, buscando desconstruir algumas formas de (res)significar o cuidado das gestantes e de seus bebês. 


\section{Contribuições dos autores}

Todas as autoras participaram ativamente de todas as etapas de elaboração do manuscrito.

\section{Direitos autorais}

Este artigo está licenciado sob a Licença Internacional Creative Commons 4.0, tipo BY (https://creativecommons.org/licenses/by/4.0/deed.pt_BR).

(cc)

\section{Referências}

1. Espinosa MCS, Lauzurique ME, Alcázar VRH, Pacheco BLC, Lubián MDCM, Cala DC, et al. Atención a la salud maternoinfantil en Cuba: logros y desafíos. Rev Panam Salud Publica. 2018; 42:e27.

2. Dominguez AE, Zacca E. Sistema de salud de Cuba. Salud Publica Méx. 2011; 53 Suppl 2:168-76.

3. Ministerio de Salud Pública. Anuario estadístico de salud. Dirección nacional de registros médicos y estadísticas de salud [Internet]. La Habana: OPAS; 2018 [citado 24 Abr 2018]. Disponível em: http://files.sld.cu/dne/files/2018/04/Anuario-ElectronicoEspa\%C3\%B1ol-2017-ed-2018.pdf

4. Osa JA. Um olhar para a saúde pública cubana. Estud Av. 2011; 25(72):89-96.

5. Madureira PSP. Sistema de saúde cubano [dissertação]. Coimbra: Faculdade de Medicina, Universidade de Coimbra; 2010.

6. Rodríguez RM, Carrión AM. Logros del hogar materno en la recuperación de peso de las gestantes. Rev Cuba Enferm. 2000; 16(2):73-7.

7. Cuba. Ley no 41, de 15 de Agosto de 1983. Ley de la Salud Pública. Gaceta Oficial de la República de Cuba. 1983.

8. Verde SV, Núñez BC, Ortiz AN, Fernández VRF. Evaluación del programa para la reducción del bajo peso al nacer en la Provincia de Santiago de Cuba. Rev Cuba Med Gen Integr. 1999; 15(5):524-31.

9. García GD. Los hogares maternos: su fundación en Cuba y objetivos propuestos desde su creación. Cuad Hist Salud Publica. 2004; (95).

10. Hernández PGP, Cabrera JH, Hernández TC, Hernández DH, Ojeda RS. Hogar materno: algunos resultados a considerar en 1996. Rev Cuba Obstet Ginecol. 1998; 24(2):99-104.

11. Fescina RH, De Mucio B, Durán P, Martínez G. El hogar materno: descripción y propuesta para su instalación. 2a ed. Montevideo: CLAP/SMR; 2011.

12. Muñiz JAG, García GD. Desarrollo histórico de los hogares maternos de Cuba. Cuad Hist Salud Publica [Internet]. 2007 [citado 24 Abr 2018]; (101). Disponível em: http://bvs.sld.cu/revistas/his/his_\%20101/his06101.htm

13. López RG, Bernal ZD. Los hogares maternos. La experiencia cubana hacia la transversalización de género y etnicidad en salud [Internet]. Cuba: OPAS; 2015 [citado 17 Ago 2017]. Disponível em: http://iris.paho.org/xmlui/bitstream/ handle/123456789/33898/Maternos.pdf? sequence=1\&isAllowed=y 
14. González EPC, García RP, González IMF, Tapia JCP, Miranda JLG, Muñiz AA. Manual de prácticas obstétricas para la Atención Primaria de Salud. Medisur. 2012; 10(5):434-65.

15. Castro E. Vocabulário de Foucault: um percurso pelos seus temas, conceitos e autores. Xavier IM, tradutor. Belo Horizonte: Autência; 2009. p. 59-60.

16. Gallo S, Veiga-Neto A. Ensaios para uma Filosofia da Educação. In: Educação. São Paulo: Segmento; 2007. n. 3, p. 16-25. (Especial Foucault Pensa a Educação).

17. Foucault M. História da sexualidade I: a vontade de saber. 13a ed. Rio de Janeiro: Graal; 1999.

18. Foucault M. Vigiar e punir. 20a ed. Rio de Janeiro: Vozes; 1999.

19. Souza CD. Educação, geografia e saúde: geobiopolíticas nos discursos da organização mundial da saúde e a produção da mundialidade pelo controle e prevenção de doenças [tese]. Porto Alegre: Universidade Federal do Rio Grande do Sul; 2014.

20. Rabinow P, Rose N. O conceito de biopoder hoje. Rev Cienc Soc Polit Trab. 2006; 24:27-57.

21. Rocha CMF. A escola na mídia: nada fora do controle [tese]. Porto Alegre: Universidade Federal do Rio Grande do Sul; 2005.

22. Foucault M. Segurança, território, população. Curso dado no Collège de France (19771978). São Paulo: Martíns Fontes; 2008.

23. Medeiros PF. Políticas da vida: entre saúde e mulher [tese]. Porto Alegre: Pontifica Universidade Católica do Rio Grande do Sul; 2008.

24. Foucault M. Resumo dos cursos do Collège de France (1970-1982). Rio de Janeiro: Jorge Zahar; 1997.

25. Gallo S. Repensar a educação: Foucault. Educ Real. 2004; 29(1):79-97.

26. Foucault M. A governamentalidade. In: Foucault M. Microfísica do poder. Rio de Janeiro: Graal; 1992. p. 277-93.

27. Portocarrero V. Instituição escolar e normalização em Foucault e Canguilhem. Educ Real. 2004; 29(1):169-85.

28. Pires PV. E "fazer tudo direitinho": cuidados e enfrentamentos nas políticas de saúde em resposta HIV/AIDS e mulheres [dissertação]. Porto Alegre: Universidade Federal do Rio Grande do Sul; 2016.

29. Organização Mundial da Saúde. Boletín de la Organización Mundial de la Salud [Internet]. Geneva: Who; 2016 [citado 24 Abr 2017]. Disponível em: http://www. who.int/bulletin/volumes/94/12/16-021216/es/

30. Organização Mundial da Saúde. Plano global para eliminar novas infecçóes por HIV em crianças até 2015 e manter suas mães vivas. Brasília: OMS; 2011. 
Maternal and child health is a healthcare priority in Cuba. This article analyzes the provision of maternal health services in Cuba's Hogares Maternos (maternity homes), where mothers are admitted in cases of high-risk pregnancy or complications. We problematize the docilization and disciplining of pregnant women, while at the same time recognizing that this process as a powerful strategy for preserving life in Cuba.

Keywords: Cuba. Mother and child health. Mother and child health centers. High-risk pregnancy. Maternal health services.

La salud materno-infantil se presenta como una de las áreas prioritarias en la atención de la salud en Cuba. El objetivo del presente artículo es analizar los servicios de salud maternal (que en Cuba se denominan Hogares Maternos) - en donde las mujeres son ingresadas para recibir cuidados médicos durante el tiempo que sea necesario en las situaciones de riesgo o de complicaciones durante el embarazo - como estrategia biopolítica. En ese sentido, buscamos problematizar la utilización de esa estrategia de docilización y disciplinamiento de las embarazadas, al mismo tiempo en que reconocemos que esta es una potente estrategia de gobierno para la preservación de la vida en Cuba.

Palabras clave: Cuba. Salud materno-infantil. Centros de salud materno-infantil. Embarazo de alto riesgo. Servicios de salud maternal. 